\title{
AMANECER EN UTØYA: UNA LECTURA ONTOLÓGICA DE LA EXTREMA DERECHA EN EUROPA
}

Luis A. Gómez Arciniega*

RESUMEN: El 22 de julio de 2011 una tragedia despertó abruptamente a Europa del ensueño democrático-liberal. Reinhard Heydrich hizo explotar una bomba en Oslo y provocó un tiroteo en la isla de Utøya. ¿Cuál es la trascendencia de lo ocurrido? Tal vez el bienestar social no impida las manifestaciones políticas extremas.

$$
\text { sose }
$$

ABSTRACT: On July 22, 2011, Europe was shook by a tragedy waking it up from its liberaldemocratic daydream. Reinhard Heydrich exploded a bomb in Oslo and caused a shootout on Utoya island. What are the implications of these incidents? Social well-being is perhaps not a deterrent to such extreme political expressions.

PALABRAS CLAVE: fascismo, Noruega, Europa, nacionalismo, lieberalismo, inmigración. KEY WORDS: fascism, Norway, Europe, nationalism, liberalism, immigration.

RECEPCIÓN: 12 de enero de 2012.

APROBACIÓN: 7 de junio de 2012.

*Consultor político. 
CITAM Derechos Reservados.

La reproducción total o parcial de este artículo se podrá hacer si el ITAM otorga la autorización previamente por escrito. 


\section{AMANECER EN \\ UTØYA: UNA LECTURA \\ ONTOLÓGICA DE LA \\ EXTREMA DERECHA \\ EN EUROPA}

A las nueve se pone el sol. Una lánguida oscuridad se posa sobre la tierra, se ven algunas estrellas, dos horas más tarde se vislumbra el fulgor de la luna. Me voy al bosque con mi escopeta y mi perro, enciendo una hoguera, y su resplandor brilla entre los troncos de los pinos.

KNUT HAMSUN

You cannot defeat Islamisation or halt/reverse the Islamic colonization of Western Europe without first removing the political doctrines manifested through multiculturalism/cultural Marxism...

ANDERS BEHRING BREIVIK

Lo ocurrido el 22 de julio de 2011 provocó una miríada de reflexiones en todos los rincones del planeta: casi un centenar de personas perdieron la vida en Noruega a consecuencia de una explosión en Oslo y de un tiroteo en la isla de Utøya; una sola persona jaló el gatillo y colocó el explosivo. El atentado reunía características que lo hacían peculiar: ocurrió en uno de los países más tranquilos de Occidente, en el seno de una sociedad homogénea racialmente y no fue perpetrado por organizaciones islámicas. La sociedad europea había soslayado las consecuencias de la Modernidad en estructuras sociales que no han acabado de despojarse de las cosmogonías nacionalistas. La realidad despertó abruptamente a Europa del ensueño democrático-liberal.

Las noticias que relataban el sangriento suceso no provenían de Afganistán o Libia, por más que los ciudadanos esperaran que el nombre 
de Noruega transmutara en la pantalla de los televisores. Sí, era el remanso escandinavo de bienestar social. ${ }^{1}$ Como para espantar sus fantasmas, Occidente clamaba: "fueron los fundamentalistas islámicos". Después de todo, después de una tragedia, siempre la negación. Es un mecanismo que tienen los seres humanos para aceptar la realidad, cuando ésta se escapa de los marcos conceptuales en los que ha sido pensada por un tiempo determinado. El caos de la realidad tiene que ser ordenado en marcos cognitivos, pues de otra forma sería imposible al ser humano resistir el embate del tiempo y dotar de sentido la serie de fenómenos cotidianos. Así, el dedo acusador señaló a una caterva de fundamentalistas imaginarios que, con turbante y cimitarras, aguardan resguardados en las cuevas la mejor oportunidad para dinamitar los pilares de la civilización occidental. ${ }^{2}$ ¡Menuda sorpresa se llevaron todos cuando un personaje con cabellos dorados, de estatura alta, tez marmórea y penetrantes ojos azules se adjudicó la autoría del atentado! Era un Reinhard Heydrich del siglo XXI.

¿Cuál es la trascendencia de lo sucedido en Noruega? Durante mucho tiempo se pensó que el bienestar social podía combatir las manifestaciones políticas extremas. Los líderes europeos de la posguerra pensaron que habían identificado el caldo de cultivo de la extrema derecha: inflación, desigualdad, olvido de los campesinos, falta de integración de los sectores rurales, pobreza urbana, desempleo... Hitler era un aborto de la complicada situación económica de los treinta. En consecuencia, se pensó que con una serie de políticas públicas como los

${ }^{1}$ Noruega ocupa los primeros lugares en varios indicadores sobre bienestar: primer lugar en el Índice de Desarrollo Humano 2011 -indicador que mide el avance promedio conseguido por un país en tres dimensiones básicas del desarrollo: disfrute de una vida larga y saludable, acceso a educación y nivel de vida digno-. Es también el país con mayor sostenibilidad ambiental, menor desigualdad de género, con menos corrupción y hasta el más feliz. PNUD, Informe sobre desarrollo humano 2011. Sostenibilidad y equidad para todos, 2011, Madrid, Transparency International, Barómetro global de la corrupción 2010, 2011, Berlín, $7^{\text {a ed. }}$

${ }^{2}$ Varias notas periodísticas de ese día apuntaron hacia una organización islámica fundamentalista como responsable del atentado. Véanse: "Doble atentado terrorista contra el Gobierno noruego", La Vanguardia, 22 de julio de 2011; Elisa Mala y J. David Goodman, “At Least 80 Dead in Norway Shooting", The New York Times, 22 de julio de 2011; Raja Abdulrahim, "Muslims feel sting of initial blame", Los Angeles Times, 23 de julio de 2011. 
fondos de cohesión o la política agrícola común se podía atajar esta situación problemática. Con lo acaecido en Noruega, se resquebraja dramáticamente la esperanza de que el Estado de bienestar per se pueda desarmar los movimientos nacionalistas extremos. Desechado lo exclusivamente económico como explicación satisfactoria del fenómeno, es menester recurrir a otras variables. Por esta razón, la propuesta de este escrito es recuperar la dimensión social de las ciencias sociales (aunque suene a pleonasmo).

Llevar a cabo un análisis ontológico entraña preguntar por el ser y no quedarse en la superficie del ente; es decir, aquí se va a inquirir por las inquietudes existenciales del ser humano del siglo XXI, que han desembocado en estas manifestaciones agresivas. El estudio supone al individuo fascinante y complejo $\mathrm{y}$, por lo tanto, imposible de reducir a un mero agente racional. Las estructuras políticas y económicas no bastan para dar una respuesta satisfactoria a este fenómeno: se necesita más profundidad; de lo contrario, se caerá en la superficie y es lo que debe evitar a toda costa un ejercicio como éste.

En las páginas siguientes, primero se describirá cómo el tema de la extrema derecha no es una novedad, sino que ha sido aplazado desde hace tiempo por los líderes políticos del continente. Después, se hará un breve recorrido por varios países de la Europa contemporánea, para contrastar las similitudes del fenómeno. Posteriormente, se propondrán algunas posibles causas de estas manifestaciones políticas. Por último, se plantearán algunos escenarios sobre el futuro de Europa. Quede sentado de una vez que, aunque la ola radical que anega el continente pudiera parecer algo exclusivamente europeo, en el fondo el tema reside en la contradicción entre ciudadanos cada vez más globalizados y resistencias étnicas cada vez más corrosivas. De la resolución de estas contradicciones pende gran parte del futuro de la humanidad.

\section{Casandra o crónica de una tragedia anunciada}

Bajo una óptica superficial podría parecer que la crisis económica y financiera es el ingrediente perfecto para la generación de movimientos extremistas. No es, sin embargo, un factor decisivo. Los Países Bajos, 
Finlandia, Noruega o Alemania, donde los discursos antiinmigración están en pleno apogeo, no se han visto golpeados por los embates financieros que sí han destrozado Grecia, Irlanda, España o Islandia. Las pulsiones nacionalistas que aún persisten en Europa son resultado de conflictos antiguos que no se han resuelto. Pensar la extrema derecha es una tarea que se ha ido postergando, ya sea por razones geopolíticas o por miedo a revivir un problema que se cree superado. Grave error sería despreciar los heraldos de una hecatombe social. Se ha venido avisando desde hace tiempo: el debate fundamental sobre el futuro de Europa versará sobre la conciliación entre ciudadanos cada vez más globales y el perenne sentido de pertenencia que, a más apertura, se enraiza con más fuerza y se vuelve más agresivo. ¿Cómo conciliar estos extremos?

Europa es un continente viejo. Con el tiempo necesitará una ingente cantidad de mano de obra migrante si quiere mantener el nivel de vida actual y esto desatará aún más tensiones sociales. Lo peor que podría ocurrir es que, como sucedió con los vaticinios de Casandra sobre la caída inminente de Troya, se desprecie el debate sobre la extrema derecha. Pese a todo, parece que esto finalmente ocurrirá. En Europa se presenciará, muy probablemente, una selffulfilling prophecy.

Muchos hablan de un "resurgimiento de la extrema derecha", pero el fenómeno que se observa hoy en día es todo menos un renacimiento. Lo que se atestigua en estos días es producto de una serie de procesos históricos complejos que, para efectos de este texto, se retomarán desde el alborear del siglo pasado. Si algo caracterizaba Europa durante las primeras décadas del siglo XX era la presencia de movimientos ultranacionalistas. A pesar de lo que quedó grabado en el inconsciente colectivo, la ultraderecha no fue ni es un fenómeno exclusivamente alemán. Es cierto que una mitología vital, una industrialización tardía, la exitosa unificación y destacar en todas las áreas del conocimiento humano hicieron difícil a este país resistirse a los impulsos hegemónicos. Más allá de estas explicaciones, lo cierto es que, al finalizar la Segunda guerra mundial, la mayoría de los actores políticos se apresuró a colocarse del lado de los "justos". ${ }^{3}$ La incongruencia e ignorancia

${ }^{3}$ Michele Battini, The Missing Italian Nuremberg. Cultural Amnesia and Postwar Politics, 2007, New York, Palgrave Macmillan, traducción de N. G. Mazhar, p. 140. 
en la forma de juzgar el comportamiento de ciertos Estados se puede apreciar en la convicción de Winston Churchill de que el nacionalsocialismo era producto del expansionismo prusiano (excusando a los austriacos de cualquier acusación de complicidad), o en el silencio generalizado sobre los alemanes expulsados o asesinados mediante una limpieza étnica en territorios húngaros, polacos, rumanos, rusos o checos. ${ }^{4}$ Tampoco existió algo parecido al Juicio de Núremberg para los líderes fascistas. ${ }^{5}$ El cabildeo italiano en Washington y las relaciones cordiales con el Vaticano garantizaron un tratamiento benevolente para el país cuna del fascismo de Mussolini.

Queda claro, pues, que el nacionalismo extremo fue y es, esencialmente, un fenómeno generalizado en Europa. Esta consideración es necesaria para poder entender con mayor lucidez la situación contemporánea. Una rápida revisión a distintos puntos del continente durante aquellos años será ilustrativa. Austria se presentó al mundo como primera víctima del nacionalsocialismo alemán en 1945, más no es necesario remontarse mucho tiempo atrás para encontrar episodios históricos significativos de la ideología que dominaba la Viena decimonónica. Georg Ritter von Schönerer, por ejemplo, fundó en 1885 un partido pangermánico que señalaba a los judíos como cómplices de los esfuerzos de la monarquía de los Habsburgo por construir un Estado multicultural, derruyendo la grandeza del Volk. ${ }^{6}$

En España, Francisco Franco se erigió como una suerte de caudillo iluminado con la tarea de salvar al catolicismo de las garras comunistas. Cuando los aviones de la Luftwaffe surcaron cielos españoles, quedó claro que la Guerra civil era el preludio de un conflicto de mayores proporciones. El "Estado corporativo autoritario" portugués de Antonio de Oliveira Salazar afirmó también los valores nacionales y justificó el sacrificio de la libertad individual en beneficio del interés superior de la nación. El Estado Novo dirigió su artillería contra el liberalismo, el comunismo y el parlamentarismo. Grecia también recorrió los sinuosos,

${ }^{4}$ Ibid., pp. 140-1.

${ }^{5}$ Loc. cit.

${ }^{6}$ Iván Ramírez, El lenguaje de la derecha radical europea, 2001, México, El Colegio de México, Jornadas, vol. 152, p. 95. 
pero seductores caminos de la extrema derecha de la mano del general Metaxas. Varias de estas dictaduras lograron sobrevivir gran parte del siglo XX gracias a una lectura geopolítica de las potencias vencedoras.

En los Balcanes también se encontraban representantes del nacionalismo extremo. La Ustaša, fundada por Ante Pavelić, fue una organización nacionalista que clamaba la supremacía étnica y religiosa del pueblo croata, al que consideraban germano y último baluarte del catolicismo occidental. Durante la Segunda guerra mundial, la Ustaša gobernó bajo la protección del Tercer Reich. Fervientemente anticomunista, el movimiento llevó a cabo un exterminio del pueblo serbio con una crueldad y celeridad tal que asustó a los alemanes y distanció al Vaticano. Asimismo, Ucrania, Hungría, Eslovaquia y la parte flamenca de Bélgica aprovecharon la oportunidad que el nacionalsocialismo les brindó para obtener ventajas territoriales y étnicas. Francia no escapó al nacionalismo extremo, marcado por el escándalo Dreyfus e incluso países neutrales como Suecia tuvieron su propia historia fascista. ${ }^{7}$

El problema se agravó cuando en la posguerra existió una distinción para los crímenes de guerra: los cometidos por los nacionalsocialistas

14 y la venganza dirigida en contra de todos los alemanes colectivamente culpables. ${ }^{8}$ Por supuesto que estas "memorias históricas" estuvieron acompañadas de dos lenguajes, códigos morales y versiones de la historia distintos. Las funestas consecuencias de este doble rasero se siguen padeciendo hasta la actualidad e impiden que se tome con seriedad el fenómeno del nacionalismo extremo en otras latitudes que no sean germanas.

${ }^{7}$ El caso sueco resulta de particular interés si se piensa que Suecia fue uno de los países menos golpeados por la Gran depresión en la década de 1930. Aún así, el Nationalsocialistiska Arbetarepartiet (NSAP) obtuvo 16,800 votos en las elecciones de 1934-35. El antisemitismo y la cuestión racial también estaban presentes en el país nórdico, como lo demuestran la formación de la Svenska Antisemitiska Foreningen (Asociación Sueca Antisemita) en 1923 y las leyes de esterilización de 1934. Lena Berggren, "Swedish Fascism: Why Bother?", Journal of Contemporary History, 2002, vol. 37, núm. 3, pp. 398-400 y passim.

${ }^{8}$ M. Battini, op. cit., pp. 140-1. 


\section{Similitudes del fenómeno nacionalista en Europa}

Grosso modo, la ultraderecha europea concibe a la sociedad de forma orgánica; entiende al Estado desde una óptica totalizadora; antepone la comunidad al individuo; denuncia la corrupción de las clases dominantes y los supuestos efectos nocivos de agentes extraños (inmigrantes, personas con cierta orientación sexual, delincuentes, etcétera), y cuestiona la legitimidad de la hegemonía liberal. Se podría decir que la extrema derecha europea recurre a un comunitarismo herderiano donde la familia, la lengua, la propia ciudad, el país y las tradiciones conforman el Volkstum, un auténtico carácter nacional. ${ }^{9}$

Se denuncia afanosamente el individualismo voraz y la impersonalidad inmoral de orden liberal que amenazan los valores necesarios para la preservación de cualquier comunidad: la responsabilidad, el autosacrificio, el parentesco, la justicia social y la solidaridad. Muestra, así, el nacionalismo su cara naturalista. A riesgo de olvidar alguna dimensión importante, a continuación se mencionarán los rasgos característicos del nacionalismo extremo contemporáneo en Europa.

\section{El bagaje teórico}

Primero es importante examinar la fuente intelectual. Casi todos los movimientos de extrema derecha contemporáneos abrevan, con matices, de la tradición organicista, corriente que consolidaron pensadores como Edmund Burke y J. Gottfried Herder y que entiende a la sociedad como una entidad biológica. Desde aquella época hasta el polifacético ultraderechista austriaco Jörg Haider, permanece inalterada la convicción de la unidad "orgánica" de la personalidad con la forma de vida que la produce; la unidad empírica y metafísica de lo físico y lo mental con el intelecto; la voluntad, los sentimientos, la imaginación, el lenguaje y la acción. ${ }^{10}$

${ }^{9}$ Isaiah Berlin, "Herder y la Ilustración”, en Berlin, Vico y Herder. Dos estudios en la historia de las ideas, 2001, Madrid, Cátedra, traducción de C. González del Trejo, pp. 204-5.

${ }^{10}$ Ibid., p. 200. 
Cabe señalar que el nacionalismo es una ideología compleja. Asimismo, es pertinente aclarar que las manifestaciones extremas de esta tendencia nada tienen que ver con la interior verdad y grandeza de esta ideología. Un buen punto de partida podría ser el Romanticismo, que influyó de manera decisiva en el nacionalismo místico. Afanosamente, los románticos rescataron los cuentos folclóricos y las canciones de las comunidades antiguas. La música brinda un ejemplo extraordinario. Richard Wagner irrumpió en la escena con su Gesamtkunstwerk-obra de arte total-y, junto con discípulos como Bruckner, exaltó el paisaje y la mitología nacional, reivindicando las virtudes del sentimiento, la sangre o la historia compartida. A escala individual, un caso paradigmático fue el del filósofo Johann Gottlieb Fichte: su pensamiento se inició en la escuela idealista kantiana, pero a raíz de la ocupación francesa fue adquiriendo matices nacionalistas hasta caer en los excesos. La historia para el romántico, a diferencia de los partidarios de la Ilustración, tiene un desarrollo propio; un espíritu o razón suprapersonal la dirigen. Los pueblos y naciones son seres orgánicos con vida propia y piezas fundamentales en el tablero de la cultura mundial. La historia, para el romántico, no es una colección de datos o de virtudes de personales heroicos, sino un reto para que una suerte de historiador-poeta encuentre el sentido oculto y profundo de los acontecimientos.

La cantera del nacionalismo romántico está compuesta por una miríada de brillantes pensadores como los ya mencionados, además de Novalis o Schlegel. ${ }^{11}$ Para Novalis, la floración de la vida espiritual no ocurre en el individuo, sino en la colectividad, en la nación-cuerpo místico u organismo internamente animado por la vida espiritual, formada por la cultura y la religión-.${ }^{12}$ La vida social de los ciudadanos es comunitaria: "una persona indivisible que piensa y siente". ${ }^{13}$ Para el organicismo nacionalista, el Estado debe estar en comunión con las fuerzas nacionales. Aquel individuo que no esté en el Estado, como la rama en el árbol, y que no participe de esa influencia generadora, no puede ser otra cosa que un salvaje. Entre el rey y su pueblo tiene que

${ }^{11}$ Gregorio de Yurre, Totalitarismo y egolatría, 1962, Madrid, Aguilar, p. 15.

${ }^{12}$ Ibid., pp. 15-23.

${ }^{13}$ Loc. cit. 
existir una unión real, como entre la cabeza y el organismo, basada en los sentimientos más diversos, en costumbres y tradiciones. Algunos autores incluso rastrearon a Rousseau y su exigencia de que la soberanía resida en el pueblo como precursor del nacionalismo organicista. ${ }^{14}$

\section{Olvido de los vínculos comunitarios: mal contemporáneo}

Durante los años treinta, Benito Mussolini escribía que "el Estado es un hecho espiritual y moral, porque concreta la organización política, jurídica y económica de la nación, y esta organización en su génesis y en su desarrollo es una manifestación del espíritu". ${ }^{15}$ En consecuencia, el empleo de metáforas y lenguaje clínico presentes en el discurso de Sarrazin, Haider o Le Pen no es fortuito, abreva de la misma fuente. Si a esto se le suma la denuncia apasionada de la corrupción que se extiende por la nación como el cáncer por los órganos del cuerpo, el cuadro debería quedar completo. Thilo Sarrazin culpó a los turcos de la decadencia espiritual de Alemania; para el Bündnis Zukunft Österreich (BZÖ) son los serbios y musulmanes los culpables; el Partidul România Mare y los húngaros mencionan a los gitanos; en el fondo, subyace un diagnóstico: se han olvidado los vínculos comunitarios en la sociedad actual. Lazos atávicos forman una comunidad donde el individuo puede alcanzar su máxima humanidad en contraposición al despiadado atomismo liberal que ha desembocado, piensan los nacionalistas radicales, en ciudades apocalípticas llenas de agentes extraños en una burda torre de Babel.

La queja primordial de la extrema derecha guarda no poca similitud con las de los movimientos fascistas en el período de entreguerras. El desdén por lo espiritual, la explicación de la historia como resultado de intereses económicos y el encumbramiento de la razón han desembocado en el olvido del vínculo de hermandad comunitaria entre los seres

${ }^{14}$ Felipe Curcó, "De la ilustración al mito: ciudadanía liberal y etnocultura nacionalista", en José Manuel Bermudo (coord.), Hacia una ciudadanía de calidad, 2007, Barcelona, Ed. Horsori, vol. 22, Cuadernos para el análisis, p. 103.

${ }^{15}$ Benito Mussolini, El fascismo. Doctrina e instituciones, 1933, Buenos Aires, Cóndor, traducción de G. García, pp. 32-3. 
humanos. Quienes reivindican el nacionalismo radical claman muchas veces que las instituciones están descarnadas, desprovistas de metas espirituales. En ese sentido, la certeza secularista de que la modernización acelerada derivará en la desaparición de la religión a escala mundial es, cuando menos, cuestionable. Siempre habrán sustitutos para la religión, pues si algo no puede abolirse es la tendencia del individuo hacia lo trascendente.

\section{Nostalgia por un pasado glorioso}

Esto es particularmente palpable en los casos de Francia y Alemania. En el primero, después de la Segunda guerra mundial, el anticomunismo y el nacionalismo a ultranza sobrevivieron encarnados en viejos fascistas de la Action Française, en nostálgicos del mariscal Pétain, en veteranos del ejército, en franceses nacidos en las colonias, etcétera. Todos estos grupos pretendían recuperar la grandeza imperial de Francia. Gran parte del discurso ultranacionalista francés abreva en la convicción de que los franceses están llamados a desempeñar un papel más relevante en el escenario internacional.

Generalmente, en Alemania, los partidos nacionalistas radicales se han centrado, además de las consabidas críticas al liberalismo en el caos de los intereses particulares, en la amenaza del multiculturalismo y en la tarea de la regeneración de la identidad alemana, despojándola del "masoquismo nacional". ${ }^{16}$ En esta línea opera, supuestamente, el periódico Junge Freiheit. El Nationaldemokratische Partei Deutschland (NPD) ha predicado la vuelta a un "völkisches Reich", el establecimiento de un nuevo orden que sitúe una Volksgemeinschaft como el ideal al que se debe aspirar.

En la región mediterránea, la ultraderecha nunca abandonó la escena italiana. El Movimiento Social Italiano (MSI) se convirtió en el bastión del nacionalismo extremo, agrupando a funcionarios de la extinta Repú-

${ }^{16}$ Hajo Funke, "Rechtsextreme Ideologien, strategische Orientierungen und Gewalt", en Stephan Braun, et al. (eds.), Strategien der extremen Rechten. Hintergründe, Analysen. Antworten, 2009, Wiesbaden, VS Verlag für Sozialwissenschaften, p. 25. 
blica de Saló, simpatizantes de Mussolini, monarquistas o clericales. Desde un principio se declaró ajeno y opuesto al "arco costituzionale", alianza de partidos defensores de la Primera república, que incluía a democristianos, socialdemócratas y comunistas. ${ }^{17}$ Defendiendo el Estado corporativo, el MSI buscaba aplicar los veintitrés puntos de Verona, la constitución ideada por Mussolini para la República de Saló y que la historia se encargó de truncar. En el origen, el movimiento apeló a clases medias rurales de granjeros, pequeños propietarios, comerciantes y artesanos amenazados por el avance del capitalismo. La supervivencia de los nacionalistas extremos quedó asegurada cuando la fuerte tradición comunista de Italia, heredera de Gramsci, se volvió una amenaza más apremiante para el liberalismo. ${ }^{18}$

\section{Rechazo y desamparo ante la alteridad}

Cualquiera que se tome la molestia de echar un vistazo al documento de Behring Breivik, "2083: A European Declaration of Independence", se encontrará con constantes reclamos hacia la actitud de los migrantes en Noruega: acosan sexualmente a las mujeres, amenazan a los caminantes nocturnos, roban los expendios de ciudadanos honrados, tiran basura en la calle, escupen las banquetas y así una larga serie de reproches, algunos verosímiles, otros francamente absurdos. Muchos de estos movimientos comparten una aversión ante la presencia alienígena casi patológica.

En Italia, la extrema derecha promovió una Ley de Seguridad sui generis. Impulsada por Maroni, y aprobada en 2008, la norma concedió poderes especiales a los alcaldes y jefes de policía para mantener el decoro de las ciudades. Eso legitimó una ofensiva étnica en toda regla. Al censo de la población romaní, menores incluídos, se sumaron desmantelamientos de chabolas sin alternativa de realojamiento, malos tratos, vejaciones policiales, reglas contra la mendicidad que contem-

${ }^{17}$ I. Ramírez, op. cit., p. 310.

${ }^{18}$ Ibid., p. 313. 
plaban la tutela de los menores por parte del Estado, nula integración escolar. ${ }^{19}$

En Francia, durante la década de los ochenta, aumentó la inmigración de africanos y musulmanes que, en muchos casos, eran refugiados políticos. Empero, a los ojos de muchos, ni la izquierda ni la derecha tradicionales tenían la firmeza para atajar el problema de la inmigración. En 1987, el 55\% de los franceses pensaba que Le Pen era el único político que decía públicamente lo que muchos pensaban en privado. ${ }^{20}$ Como bien menciona Pascal Perrinau, prescindiendo de la clásica división ideológica, el modelo republicano francés tiene poco de multicultural y, con el tiempo, ha sido incapaz de integrar a los extranjeros. ${ }^{21}$

El Partido Popular Danés (Dansk Folkeparti), por echar un vistazo a Escandinavia, se ha abocado a combatir el multiculturalismo y a defender la monarquía y la Iglesia luterana danesa. A pesar de que su táctica ha sido mantenerse al margen del Gobierno, muchas de sus políticas acaban siendo puestas en práctica. Dinamarca cuenta en la actualidad con una de las legislaciones más duras sobre inmigración. En Suecia, un partido con raíces ultranacionalistas logró el año pasado el 5,7\% de los votos. Ahora se muestran exultantes ante la victoria de sus colegas finlandeses: "Claro que podemos pensar en líneas de trabajo conjuntas, ya sea en el Consejo Nórdico o en la Unión Europea. También podemos mantener relaciones informales donde podemos aprender de nuestras experiencias mutuas". ${ }^{22}$

\section{Nueva generación y nuevas tecnologías}

Es común también la presencia de un nuevo tipo de líderes, que poco tienen que ver con sus predecesores. Los nuevos políticos populistas son más jóvenes -la mayoría rondan los cuarenta-, más modernos y mejor

${ }^{19}$ Miguel Mora, "Umberto Bossi o el odio al diferente”, El País, 1 de mayo de 2011.

${ }^{20}$ I. Ramírez, op. cit., p. 287.

${ }^{21}$ Pascal Perrineau, "La peculiaridad de la extrema derecha francesa en Europa", Foro Internacional, 1999, vol. 39, núm. 1, traducción de L. Murillo, pp. 14-6.

${ }^{22}$ Adrián Soto y Ana Carbajosa, "El ocaso de la tolerancia nórdica", El País, 1 de mayo de 2011. 
parecidos. Son carismáticos y tienden a ser grandes oradores. Consiguen, además, desmarcarse del turbio pasado de sus formaciones cuidando su lenguaje, con el que son capaces de transmitir ideas xenófobas sin incurrir en el lenguaje zafio del pasado. Han conseguido, en definitiva, hacer aceptables y digeribles ideas que, hasta hace poco, eran repudiadas por completo en la escena política.

El ascenso de nuevos personajes populistas de la derecha radical luce incontenible. Pia Kjærsgaard, Geert Wilders, Viktor Orbán representan a una nueva generación que se consolida en puestos políticos desde los Países Bajos hasta Hungría, pasando por Dinamarca, Reino Unido, Austria y Bélgica. El simpatizante del nacionalismo extremo es un ser humano trabajador, ligeramente conservador, que cumple con la ley y que, en silencio, observa con creciente resentimiento cómo "su mundo" se empieza a extrañar por progresistas, criminales y alienígenas. ${ }^{23}$

Las redes sociales también fungen como una excelente herramienta organizativa para la derecha populista. Los partidos y movimientos más conocidos de este lado del espectro político reúnen casi 437,000 seguidores en Facebook: el Partido Nacional Británico tiene 82,700 seguidores; el Freiheitliche Partei Österreichs (FPÖ), 84,000; la Lega Nord italiana, 45.000; el Front National, 35,000; y el Partido del Progreso Noruego, $64,000 .^{24}$

\section{Fuentes del malestar nacionalista contemporáneo}

Resulta pertinente adentrarse en aquello que nutre estas expresiones de malestar. Cuando se discute el tema de la extrema derecha en Europa es necesario empezar por reconocer que este fenómeno no es una enfermedad, ni el liberalismo el remedio. Tiene razón Žižek cuando afirma que se trata del reverso de la moneda. ${ }^{25}$ Si hoy es posible hablar de skin heads es porque Kant abrió filosóficamente la posibilidad de su

${ }^{23}$ Oliver Geden, "Die Renaissance des Rechtspopulismus in Westeuropa”, Internationale Politik und Gesellschaft,2006, vol. 12, núm. 2, p. 98.

${ }^{24}$ Jamie Bartlett, et al., The New Face of Digital Populism, 2011, London, Demos, pp. 33-41.

${ }^{25}$ Slavoj Žižek, "Eastern European Liberalism and Its Discontents", New German Critique, 1992, núm. 57, pp. 30-2. 
existencia. Al concebir la relación entre el bien y el mal como contraria, en el caso de oposición "real", Kant está forzado a aceptar la hipótesis del "mal radical", es decir, de la presencia en los humanos de una fuerza que contrarresta la tendencia hacia Dios plasmada en el imperativo categórico. ${ }^{26} \mathrm{El}$ liberalismo hegemónico falla en su intento por abatir a los nacionalistas extremos porque, inmerso en la racionalidad, no atina a sospechar de dónde proviene la fuerza vital de estos movimientos.

Vale la pena mencionar que el malestar de la Modernidad, expresado en los nacionalismos radicales, es un estado mental, una forma de percibir el mundo y el entorno. Fruto de una concepción de Leistungsgesellschaft, ${ }^{27}$ incluso el trabajo se ha vuelto una fuente de inseguridades humanas. ${ }^{28}$ Un mundo crecientemente interconectado ha hecho la competencia más feroz y se debe responder diligentemente a los cambios de la demanda; el individuo no se puede relacionar con su trabajo como lo hacía el artesano ancestral. El mundo contemporáneo desprecia las necesidades trascendentes del ser humano y, por consiguiente, está imposibilitado para satisfacerlas. Las sociedades liberales han quedado reducidas a un conglomerado de personas que tratan incesantemente de especializarse, de dominar la labor que se les asigna; siempre temerosas de que alguien más dotado ocupe su lugar, buscan acuciosamente adquirir un cúmulo de conocimientos prácticos para sentir que no son fácilmente reemplazables, aunque de hecho lo sean. ${ }^{29}$ Los individuos se vuelven muy distintos entre sí y se diluye el sentido comunitario. Los objetivos e ideales personales se erigen como valor supremo, cayendo en un solipsismo aterrador. La alienación es el pan de cada día. Muchos trabajos se vuelven prescindibles por el avance tecnológico. Visto desde otra perspectiva, el trabajo, ahora entendido como una meta per se, trae consigo un tren de vida de lujos y altera las funciones de organizaciones sociales como la familia.

${ }^{26}$ Ibid., p. 32.

${ }^{27}$ Este término se traduce al español generalmente como "sociedad de rendimiento".

${ }^{28}$ Charles Taylor, Fuentes del yo. La construcción de la identidad moderna, 2006, Barcelona, Paidós, Surcos vol. 21, traducción de Ana Lizón, p. 678.

${ }^{29}$ I. Ramírez, op. cit., pp. 176-7. 
En la misma tónica, la lógica económica liberal ha terminado por entronizar lo efímero. Se reemplaza lo perdurable por mercancías rápidas y desechables que rodean al ser humano, afectando también el modo en el que se reproducen las estructuras sociales: "Contrasta lo que implica hoy calentar nuestras casas con la actual calefacción central, con lo que la misma función suponía en tiempos pioneros, cuando toda la familia tenía que colaborar con cortar y almacenar la leña, en alimentar las estufas y calderas, y cosas similares". ${ }^{30}$ Carreteras, supermercados, viaductos o vías rápidas sustituyen los espacios de convivencia. El ser humano queda relegado a las cuatro paredes de su habitáculo. El individuo se enfrenta a la soledad más terrible: un mundo de mercancías modernas. $^{31}$

Ciertamente, el liberalismo ha sido incapaz de elaborar un discurso que satisfaga las necesidades trascendentes del individuo. Peor aún, éste ha tenido como consecuencia, incluso, el debilitamiento de los lazos comunitarios que dotan de significado la vida cotidiana. Por esta razón, cabría señalar que el liberalismo es el principal artífice de su fracaso. Como bien apunta Žižek, los jemeres rojos y los senderistas son el juicio infinito del capitalismo tardío y, por lo tanto, en términos hegelianos, son una parte integral de la noción misma: si uno quiere constituir el capitalismo como un sistema mundial, se debe tomar en cuenta su negación inherente: el fundamentalismo, así como su negación absoluta. ${ }^{32}$

La evolución del pensamiento técnico ha contribuido en gran medida a desatar la reacción del pensamiento tradicional. La tecnología es la expresión del poder por el poder que, en la práctica, deriva en la ciencia positiva, el desarrollo tecnológico, el trabajo industrial, el Estado burocrático, la maquinaria bélica tecnificada, la cultura administrada, la dictadura de la opinión pública y la civilización urbana de masas. ${ }^{33}$ Hoy en día, la ciencia moderna, distanciándose de las ciencias

${ }^{30} \mathrm{C}$. Taylor, op. cit., p. 677. Incluso la arquitectura, salvo escasas honorables excepciones -la Sagrada Familia de Gaudí-, se ha contagiado del Zeitgeist de lo desechable.

${ }^{31}$ Loc. cit.

${ }^{32}$ S. Žižek, op. cit., p. 41.

${ }^{33}$ Jürgen Habermas y John McCumber, "Work and Weltanschauung: The Heidegger Controversy from a German Perspective”, Critical Inquiry, 2008, vol. 15, núm. 2, p. 445. 
filosóficas antiguas, culmina un proceso iniciado con Galileo, cuando el marco metodológico de referencia refleja el punto de vista trascendental de la posible disposición técnica. Fruto del mecanicismo desatado por Leibniz, se ha abandonado tanto al prototipo de físico observador de la naturaleza como las innovaciones espontáneas. Ahora, por el contrario, el progreso técnico y científico está inserto en una lógica de producción y afán de dominio constantes. Difícilmente hubiera sospechado el hombre que, víctima de su megalomanía, caería sometido por las máquinas que el mismo creó. Éstas han sido más terribles que cualquier novela futurista, pues el individuo es incapaz de atinar mediante qué oscuros artilugios se le priva de su libertad.

Finalmente, no debe soslayarse lo primordial: actualmente ya no queda nada que otorgue un profundo y potente sentido de propósito a la existencia. El modo instrumental de vida, al disolver las comunidades tradicionales o excluir modos anteriores de vida con la naturaleza menos instrumentales, destruye las coordenadas de significado. La "jaula de hierro" weberiana apunta a las exigencias para la supervivencia en una sociedad capitalista o (tecnológica), las cuales dictan un patrón de acción puramente instrumental que produce el inevitable efecto de destruir o marginar los propósitos de valor intrínseco. ${ }^{34}$ La pérdida de significado puede formularse de otras maneras. Max Weber, recogiendo el tema de Schiller, habla del "desencanto" (Entzauberung) del mundo. ${ }^{35}$ Éste ha perdido su condición hierática y ha quedado reducido a un ámbito neutro de potenciales medios para alcanzar propósitos. Una forma de gobierno tecnocrática impide una verdadera representación de los ciudadanos, ya que, al definir los sistemas sociales sobre criterios económicos, la política deja de ser la instancia clásica de praxis y lexis y termina convirtiéndose en una parcela más de la mentalidad científico-técnica, dominada por expertos y burócratas. ${ }^{36}$

${ }^{34}$ C. Taylor, op. cit., pp. 675-6.

${ }^{35}$ Ibid., p. 676.

${ }^{36}$ José Carabante, "Retos de la filosofía política en el siglo XXI”, en Paloma Núñez y Javier Espinosa (coords.), Filosofía y política en el siglo XXI. Europa y el nuevo orden cosmopolita, 2009, Madrid, Akal, p. 329. 


\section{Epílogo: ¿Europa al borde del abismo?}

Lo ocurrido en la isla de Utøya debe ser asimilado como una oportunidad para reflexionar sobre las necesidades trascendentes de los individuos que el liberalismo hegemónico no ha podido satisfacer y que encuentran una válvula de escape en movimientos de extrema derecha. Difícilmente podrá encontrarse otro lugar en el planeta donde se hayan alcanzado los niveles de bienestar social que se han alcanzado en Europa. Por esta razón, es importante descartar, de una vez, la hipótesis que sostiene que la raíz de los movimientos extremistas puede ser disecada mediante prestaciones sociales y bienestar económico. Esto no implica que el Estado de bienestar deba ser demolido sin más. De hecho, la lectura que se hace de la crisis económica actual es errónea. Los retos que el continente tiene ante sí no se resolverán mutilando el entramado de prestaciones sociales. El individuo necesita una épica que dote de significado la realidad. Será prácticamente imposible alcanzar esto si sólo se piensa en términos de productividad, competitividad, rendimiento, avance tecnológico o especialización. Restañar los vínculos comunitarios desde el núcleo familiar, bajo el cuidado de un Estado que fomente la igualdad de género, el respeto al ambiente, el ocio productivo y la educación, tiene que ser una tarea impostergable. Asimismo, las políticas públicas deben procurar que el ser humano se adapte a un mundo histórico preexistente y abandonar la avidez por el sometimiento y dominio técnico de cualquier manifestación de vida.

Hace más de setenta años, Heidegger advertía a los europeos que Europa yacía bajo una tenaza que compartía en sus dos extremos la furia desesperada por el desencadenamiento de la técnica y la organización abstracta del ser humano. ${ }^{37}$ El transcurso de los años no ha mermado la vigencia de la reflexión heideggeriana. Al final del día, le corresponde a Europa moderar los excesos liberales y encontrar la forma de atemperar (que no exterminar, pues es imposible) las manifestaciones nacionalistas. En la década de los treinta, Heidegger dele-

${ }^{37}$ Martin Heidegger, Introducción a la metafisica, 1956, Buenos Aires, Nova, traducción de E. Estiú, p. 73. 
gaba en Alemania - en su calidad de pueblo metafísico- la tarea de detener la decadencia espiritual de la Tierra y permitir el despliegue de nuevas fuerzas histórico-espirituales. ${ }^{38} \mathrm{Hoy}$, el pueblo alemán, corazón del continente europeo, ha sustituido la política exterior de Lebensraum, tan representativa del siglo XX, convirtiéndose en el motor de la integración europea.

Allende lo que los escépticos puedan proclamar sobre el modelo europeo, hay una serie de hechos que no deben soslayarse. Europa sería la única alternativa para contrarrestar la peligrosa y alienante ortodoxia liberal (con sus consabidos conceptos apéndices: productividad, competencia, rendimiento, bienestar medido por medio del PIB). En franco contraste con los demás actores globales, los europeos han optado por un estilo de vida. Han renunciado a un cierto nivel de crecimiento potencial a cambio de más tiempo libre del que disfrutan la mayoría de estadounidenses y, aun así, la productividad de algunos países europeos es comparable a la de Estados Unidos. China e India basaron gran parte de su crecimiento en tener salarios más bajos y en una disponibilidad abrumadora de mano de obra barata. Aunque estos países estén creciendo vigorosamente en el terreno económico, aún tienen graves de26 ficiencias: su infraestructura de transportes sigue siendo caótica; sus desigualdades, tanto entre familias como entre regiones, son abismales; están plagadas de megalópolis con los índices de contaminación más altos del mundo.

El nacionalismo no va a desaparecer; es imposible erradicarlo como fuente de sentido de la experiencia humana. En todo caso, habría que reducir las pretensiones de contener las manifestaciones extremas de dicha ideología. En ese sentido, la mera prohibición no ha tenido el éxito esperado. Si se considera la hegemonía estadounidense en el escenario internacional, respaldada por un poder militar sin parangón, resulta poco probable que el liberalismo abdique de su posición como ideología dominante. No obstante, de seguir por este camino, las contradicciones de esta visión del mundo continuarán alimentando al nacionalismo

${ }^{38}$ Ibid., pp. 73-4. 
extremo. Si el liberalismo quiere sobrevivir, necesita reinventarse, moderarse e incorporar elementos que han hecho tan atractiva la oferta del nacionalismo extremo. Quizá en un futuro cercano carezca de sentido hablar de ideologías como liberalismo, nacionalismo, socialismo, socialdemocracia o democracia cristiana. Probablemente, el destino de la humanidad dependa de que estos discursos políticos se moderen y complementen, con el fin último de dotar de un significado más poderoso la cada vez más ajena realidad contemporánea. 
CITAM Derechos Reservados.

La reproducción total o parcial de este artículo se podrá hacer si el ITAM otorga la autorización previamente por escrito. 